\title{
ALGUNOS ARGUMENTOS A FAVOR DE UNA CIENCIA JURÍDICA INTERPRETATIVA*
}

\author{
Aldo Schiavello \\ Università degli Studi di Palermo (Italia)
}

RESUMEN. La ciencia jurídica de matriz iuspositivista establece un ligamen preciso entre el derecho y el lenguaje. Según esta perspectiva, el derecho es el discurso del legislador y la ciencia jurídica no es otra cosa que un discurso sobre un discurso: un metalenguaje descriptivo del lenguaje prescriptivo del legislador. Esta concepción del derecho y este modelo de ciencia jurídica están en crisis desde hace algunas décadas. En mi artículo presento cuatro argumentos dirigidos a señalar los límites de esta aproximación al derecho: el argumento epistemológico, el argumento del pluralismo epistemológico, el argumento del giro interpretativo y, finalmente, el argumento funcionalista. Estos argumentos no están todos al mismo nivel y no tienen todos la misma fuerza. Algunos proporcionan sólo una explicación de por qué la ortodoxia iusanalítica sobre la ciencia jurídica esté siendo atacada. Otros tienen la pretensión de identificar algunos límites estructurales y conceptuales de este modelo.

Palabras clave: Ciencia jurídica, descriptivismo, pluralismo metodológico, giro interpretativo.

\section{Some arguments supporting an interpretative approach to legal knowledge}

ABSTRACT. Legal positivism's conception of legal knowledge sets up a tight bond between law and language. According to this perspective, law is the discourse of the legislator and legal science is nothing but a discourse on a discourse: a meta-language descriptive of the prescriptive language of the legislator. This conception of law and this model of legal science have been in crisis for some decades. In my paper I present four arguments serving to underline the limits of this approach to law: the epistemological argument, the argument of epistemological pluralism, the argument of the interpretative turn, and lastly the functionalist argument. These arguments are not all on the same plane and do not all have the same strength. Some only furnish an explanation of why analytical law orthodoxy on legal science is under attack. Others claim to identify some structural and conceptual limits of this model.

Keywords: Legal knowledge, descriptivism, constructivism, methodological pluralism, interpretive turn.

\footnotetext{
* Fecha de recepción: 27 de abril de 2014. Fecha de aceptación: 14 de mayo de 2014.
} 


\section{PREMISA}

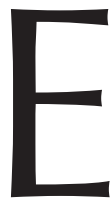

1 tema de la ciencia jurídica o, para ser más precisos, del «carácter científico» de la jurisprudencia (en su acepción de prudentia o sapientia juris), además de ser un tema clásico de la reflexión iusfilosófica ${ }^{1}$, ha marcado el nacimiento de la Escuela analítica italiana de filosofía del derecho desde principio de los años cincuenta del siglo pasado, a partir de la publicación, por Norberto BoBBio, de su ensayo Scienza del diritto e analisi del linguaggio ${ }^{2}$, un verdadero y propio «manifiesto programático» ${ }^{3}$ del nuevo curso iusfilosófico.

Las tesis de fondo compartidas por los exponentes de esta Escuela (en especial por BOBBIO, SCARPELLI y TARELLO) se pueden resumir de una forma eficaz tomando prestadas las palabras de Riccardo GUASTINI: «el derecho no es otra cosa que un discurso: las normas son comunicaciones lingüísticas prescriptivas, es decir enunciados (ni verdaderos, ni falsos) dirigidos a modificar la conducta humana. Por consiguiente, la ciencia jurídica es [...] no una enigmática ciencia "normativa", sino simplemente un análisis lingüístico: en concreto, el análisis del discurso legislativo. Puesto que se reduce a la ciencia jurídica [...] a un "discurso sobre otro discurso": un metalenguaje descriptivo, en el que el lenguaje-objeto es el discurso prescriptivo del legislador» ${ }^{4}$.

Es oportuno recordar que, a excepción del acuerdo de máximos sobre estas tesis metodológicas y/o meta-metodológicas, la Escuela analítica italiana se ha dividido en muchas corrientes, a partir de la divergencia fundamental entre la versión normativista y la versión iusrealista ${ }^{5}$. Esto ha provocado un rico debate entre los distintos exponentes de esta Escuela, un debate que con el tiempo ha ido esclerotizándose y agotándose (se trata, obviamente, de una opinión personal): cada uno de los participantes desarrolla diligentemente su papel en la comedia sin ofrecer ninguna sorpresa a la platea ${ }^{6}$.

Mi impresión es que son precisamente los presupuestos de fondo los que sería necesario revisar, o al menos deberían ser el objeto central del debate ${ }^{7}$. Desde los años cincuenta del pasado siglo muchas cosas han cambiado: la globalización ha provocado (entre muchas cosas) la crisis del modelo jurídico basado en la soberanía de los Estados nacionales; el neoempirismo ya no representa la corriente principal en el ámbito

1 Se puede consultar por ejemplo KiRChMAnN, 1964: 3-35. Para una reconstrucción general de la evolución de la ciencia jurídica desde una perspectiva histórica, vid. SAMUEL, 2003.

2 Ahora en BOBBio, 2011: 1-31.

3 Tal y como lo califica PATTARO, 1976: 455.

4 Guastini, 2011a: XIII. Vid. también TrOPER, 2003: 19-52. Un discurso aparte merecería en este punto Uberto SCARPELLI, cuyas tesis sobre la ciencia jurídica resultan desde el principio heterodoxas y, en mi opinión, previdentes. Vid. en su caso SCHIAVELlO, 2004: 77-89.

5 Para una breve pero completa reconstrucción de este debate, vid. PINTORE, 1994: 243-264. Para una reconstrucción más detallada, vid. CHIASSONI, 2005: 63-101.

6 Para una reconstrucción exhaustiva y puesta al día de este debate, se puede ver la discusión entre CoMANDUCCI, 2004; FERRAJOLI, 2004a y 2004b; GUASTINI, 2004, y JORI, 2004. El reciente JORI, 2010 en mi opinión puede ser considerado un paso importante en la dirección correcta.

7 La influencia, en la conformación de tal impresión, de la perspectiva iusfilosófica de Vittorio ViLLA, que con mucho se podría calificar de heterodoxa, es tan evidente que únicamente requiere de un pequeño apunte en esta nota. 
epistemológico y también el debate iusfilosófico contemporáneo ha seguido (y está siguiendo) direcciones divergentes respecto a las emprendidas por la escuela analítica italiana. Y se podría continuar.

De ahí, la idea de un manifiesto de una ciencia jurídica «interpretativa», en el que se establezca como objetivo discutir algunas de las tesis de fondo de la perspectiva iusanalítica. No se trata ni de una idea original ni tampoco revolucionaria. El «cambio interpretativo» es uno entre los muchos cambios que han caracterizado a la filosofía (y la filosofía del derecho) contemporánea ${ }^{8}$. Además, la idea de que el derecho sea interpretación y que la ciencia del derecho se resienta de esta característica de su objeto se ha convertido en un tópico del debate iusfilosófico contemporáneo, sobre todo gracias a (o, por los «resistentes», por culpa de) Ronald DwORKIN. El hecho de que una perspectiva filosófica esté de moda no implica que sea correcta. Todavía, es necesario resistir también a la tentación —ante la que ceden en ocasiones algunos iusfilósofos analíticos- de mirar con sospecha y de no tomar demasiado en serio aquellas ideas que desafían a sus convicciones más consolidadas y, por tanto en cuanto tales, más tranquilizadoras.

\section{CIENCIA JURÍDICA Y EPISTEMOLOGÍA}

Una reflexión completa sobre la ciencia jurídica debe plantearse desde consideraciones epistemológicas generales. En este artículo, también, este aspecto se abordará en pocas líneas; de hecho se considera, no obstante alguna petitio principii de algunos participantes en el debate y sin tener en cuenta posiciones ingenuas o excéntricas, que sea posible encontrar una convergencia sustancial de máxima entre los estudiosos del derecho sobre la epistemología que se debe adoptar. Además, la independencia de la ciencia jurídica del sentido común sugiere desarrollar un discurso completo de la ciencia jurídica que prescinda de un cuadro epistemológico con un fondo excesivamente complicado (vid. también el apdo. 6). Las divergencias entre las perspectivas epistemológicas probablemente son más significativas en relación con las ciencias naturales; en esta sede todavía es prudente circunscribir este discurso únicamente a la ciencia jurídica.

Simplificando, las posiciones epistemológicas en este ámbito se pueden reconducir a dos: el empirismo (o descriptivismo) y el constructivismo?.

El empirismo presupone el realismo metafísico, esto es la convención, no verificable empíricamente, de que exista un mundo externo independiente de los sujetos que conocen. Además, el empirismo considera que la función del lenguaje del conocimiento sea la de (tender a) representar la realidad «así como es». Para el empirismo, la mente humana funciona como un espejo capaz de «reflejar la realidad» ${ }^{10}$. En otras palabras, para el empirismo la realidad (la realidad en sí misma) es el último juez de la

8 Sobre la «actitud» de la filosofía contemporánea frente a los cambios, vid. TUZET, 2005: 43-44. Utiliza por primera vez la expresión «giro interpretativo» en el ámbito iusfilosófico KRESS, 1987: 834-860.

9 En este punto sigo la óptima reconstrucción de COMANDUCCI, 2008: 419-423. Para un análisis más articulado y convincente de las diferencias entre el descriptivismo y el constructivismo vid. VILLA, 1999.

10 Vid. RORTY, 1986. 
corrección de nuestro conocimiento: entre la ontología y la epistemología el énfasis se pone sobre la primera.

El constructivismo no niega necesariamente el realismo metafísico. Esta perspectiva considera, sin embargo, que la actividad cognoscitiva no pueda trascender el fondo constituido por la forma en la que funciona nuestro lenguaje y, de forma más general, no pueda trascender nuestros esquemas conceptuales. El constructivismo «moderado» no duda de que el objeto del conocimiento sea la realidad, pero precisa que la realidad que es objeto de conocimiento siempre es una «realidad para nosotros» y no la «realidad en sí misma».

El constructivismo «radical», por el contrario, es antirrealista, lo que distingue, al menos a primera vista esta perspectiva del escepticismo es el énfasis que pone el constructivismo sobre la existencia de un lenguaje compartido y de esquemas conceptuales comunes. Es precisamente la existencia de determinados esquemas conceptuales compartidos-que no son ni verdaderos ni falsos y que, por tanto, podrían ser diferentes de aquello que en realidad son-lo que permite en definitiva distinguir entre creencias verdaderas y falsas. El problema, en un planteamiento de este tipo, no es el énfasis que se pone en la necesidad de un filtro - un filtro representado por el lenguaje y los esquemas conceptuales - entre la mente humana, el pensamiento, por una parte, y el mundo, por otra, sino la tesis, mucho más exigente y atribuible al idealismo, de que la corrección o no de nuestras creencias no depende, en ningún sentido, de cómo es el mundo ${ }^{11}$.

El antirrealismo contrasta con la intuición de fondo según la cual en los estados de la intención que expresan creencias sobre el mundo se puede distinguir entre aquellos correctos e incorrectos sólo con la condición de aceptar una forma, aunque sea mínima, de empirismo. En otras palabras, nuestras afirmaciones sobre el mundo y sobre la realidad pueden tener un sentido, ser verdaderas o falsas, únicamente con la condición de que el «tribunal de la experiencia» ${ }^{12}$ sea capaz de desempeñar un papel de mediación entre nuestra mente y el mundo. En caso contrario, lo único que nos queda es una especie de «escepticismo plural» que se diferencia del relativismo tradicional porque determina la «medida de todas las cosas» no ya en el ser humano individual, sino en la sociedad en su conjunto. Por consiguiente, el conocimiento, la posibilidad de conocer, ya no sería una ilusión individual sino colectiva. Pero en todo caso continuaría siendo siempre una ilusión.

Sin embargo, el antirrealismo, no es una tesis compartida por todos los constructivistas. Tal y como antes ya he precisado el constructivismo no implica el antirrealismo ${ }^{13}$.

Por el contrario, no todos los empiristas son ingenuos. Paolo COMANDUCCI, por ejemplo, está dispuesto a admitir que «la correspondencia o no de nuestras proposi-

11 Vid. WiLliams, 1988: 279-296.

12 «El dogma del reduccionismo sobrevive en la suposición de que cada proposición, considerándola de forma aislada de las demás, pueda ser objeto siempre de confirmación o refutación. Mi sugerencia [...] es que nuestras proposiciones sobre el mundo externo siempre se encuentran frente al tribunal de la experiencia sensible no individual, sino solo como una asociación» (QUINE, 1969: 884-885).

13 A fin de conocer una perspectiva constructivista y no precisamente antirealista vid. por ejemplo VILLA, 1993: 210-216, además del ya citado VILLA, 1999. 
ciones con la realidad está influenciada por la configuración del objeto de que se trate. Se llega así a sostener que, en cierta medida, la ontología dependa de la epistemología, no en el sentido - típico del constructivismo más radical - de que toda la realidad sea dependiente del sujeto, sino en el sentido de que nuestros criterios heurísticos (no nuestro concepto de verdad) sean necesariamente coherentes» ${ }^{14}$.

En conclusión, si es verdad que pocos juristas niegan la existencia de una realidad jurídica externa y el papel necesario del lenguaje y de los esquemas conceptuales en la representación de la realidad, entonces no resulta oportuno enfatizar la contraposición entre el empirismo y el constructivismo. Tal contraposición adquiriría una importancia crucial en el caso de que el constructivismo radical y el empirismo ingenuo no representasen — como de hecho representan — posiciones marginales en el debate iusfilosófico contemporáneo sobre la ciencia jurídica.

\section{LA CIENCIA JURÍDICA Y SU OBJETO}

El pluralismo metodológico es una tesis (casi) de manera unánime aceptada por la epistemología contemporánea. Según esta tesis, que contradice el monismo metodológico del neopositivismo más intransigente, la posibilidad de cualificar como «científico» un ámbito del conocimiento no pasa por la adopción de un método determinado, en particular el método de las ciencias empíricas maduras ${ }^{15}$. La idea, banal, es que el método depende del contexto o, en otras palabras, que es el ámbito de la experiencia objeto del estudio el que determina cual sea el método adecuado que se tiene que adoptar.

En general, una investigación meta-metodológica nos llevará a distinguir de un modo más bien neto el método de las ciencias naturales de aquel de las ciencias humanas. Las razones son, una vez más, obvias. Aquí las resumo afirmando que en el ámbito de las ciencias naturales la distancia entre el objeto de estudio y la actividad cognoscitiva es más amplia de cuanto sea, fatalmente, en el ámbito de las ciencias humanas. Estas últimas, de hecho, se ocupan de acontecimientos humanos los cuales, a diferencia de los hechos naturales, se «construyen» ${ }^{16}$ por los seres humanos y, precisamente por esto, no son impermeables a la actividad cognoscitiva que les atañe. El científico social es en cierto modo un actor o un «constructor» en el ámbito de la experiencia que representa el objeto de su estudio.

Si aceptamos la tesis de que el objeto de estudio influye sobre el método científico, entonces un discurso sobre la ciencia jurídica - y una defensa de una ciencia jurídica «interpretativa»— impone la realización de una breve reflexión preliminar sobre el objeto de la ciencia jurídicas es decir, sobre el derecho.

14 COMANDUCCI, 2008: 422-423, cursivo en el original; vid. también JORI, 1985: 423-426.

15 Para una presentación más completa de la contraposición entre monismo y pluralismo metodológico y para una defensa argumentada sobre este último se puede consultar la obra pionera de VILLA, 1984: 24-45. Vid. también VILLA, 2004: 1-43 y VILLA, 2013: 374-398. El pluralismo metodológico es también una de las tesis centrales de la filosofía hermenéutica y por tanto representa un punto crucial de intersección entre tradiciones filosóficas (y iusfilosóficas) diferentes. Vid. GADAMER, 1983 y, por lo que respecta al ámbito iusfilosófico VIOLAZACCARIA, 1999: 105-173 y ZACCARIA, 2012.

16 Vid. SEARLE, 1996. 
Definir qué es el derecho o delimitar el ámbito jurídico no es simple. Herbert HART parte precisamente de una reflexión sobre la dificultad de definir el derecho para elaborar su versión del positivismo jurídico.

Pocas preguntas referentes a la sociedad humana han sido formuladas con tanta persistencia y respondidas por pensadores serios de maneras tan diversas, extrañas, y aun paradójicas, como la pregunta «¿qué es derecho?». Aunque limitemos nuestra atención a la teoría jurídica de los últimos ciento cincuenta años, y dejemos a un lado la especulación clásica y medioeval acerca de la «naturaleza» del derecho, nos daremos con una situación que no encuentra paralelo en ningún otro tema estudiado en forma sistemática como disciplina académica autónoma. No hay una vasta literatura consagrada a contestar las preguntas «¿Qué es la química?»o «¿Qué es la medicina?», como la hay para responder a la pregunta «¿Qué es el derecho?» ${ }^{17}$.

El desacuerdo, también radical, sobre la definición del derecho nos dice mucho sobre la naturaleza de este último y representa un indicio a favor de una ciencia jurídica interpretativa. Sin embargo, en este punto me interesa poner de manifiesto una característica no controvertida del derecho (vid. apdo. 6).

Todas las concepciones del derecho que se dividen, también radicalmente, sobre la definición de derecho, atribuyen al derecho (y, en general, a los sistemas normativos) la función de influir sobre el comportamiento humano ${ }^{18}$. Usando una feliz expresión formulada por Joseph RAZ y cuyo uso se ha generalizado, el derecho proporciona razones para actuar. Si se asume que el derecho realiza esta función, entonces es necesario preguntarse qué comporta esto para la ciencia jurídica. Una consecuencia particularmente no muy controvertida, al menos a partir de HART, es que el estudioso del derecho no pueda prescindir, a la hora de reconstruir el derecho o un aspecto particular del mismo, del punto de vista del participante, es decir, del punto de vista de quien considera el derecho como una justificación de sus propias acciones.

Más controvertido es, en cambio, establecer que grado de compromiso se le requiera al estudioso del derecho que debe rendir cuenta de la perspectiva del participante. Algunos estudiosos sostienen que sea posible, y además oportuno, registrar como un mero dato la necesaria existencia de «participantes» en la práctica jurídica, evitando con cuidado caer en la órbita de quien considera el derecho una razón para la acción.

No se tiene que dar por descontado que el estudioso del derecho pueda adoptar una perspectiva «indiferente» de este tipo. A fin de evitar esta posibilidad se pueden aducir, además de las buenas razones a favor del constructivismo moderado que ya se ha discutido en el párrafo precedente, también razones más específicas que pongan el acento sobre el hecho de que la perspectiva del participante es compleja y articulada y, debido a ello, cualquier tipo de reconstrucción de dicha perspectiva implica que el estudioso deba tomar decisiones y realizar valoraciones que lo transforman en un participante, ya sea virtual o auxiliar ${ }^{19}$.

17 HART, 1992: 1.

18 Vid. Moreso y Vilajosana, 2004: 21-60; Raz, 2005b: 334-337.

19 Vid. RAZ, 2005a: 313-315 y FINNIS, 2000: 37-57. FinNIS, a diferencia de RAZ, está convencido que las valoraciones que se le piden al estudioso del derecho tengan una naturaleza moral. Vid. en su caso SCHIAVELLO, 1998 y SCHIAVELLO, 2002. 
Mi impresión, sin embargo, es que plantear la cuestión de esta forma nos aleja del punto que es realmente importante. La pregunta interesante no es si es posible una ciencia jurídica que mantenga las distancias de la práctica jurídica sino si una ciencia jurídica que presente estas características debe fomentarse en el caso de que fuera posible.

Considero que la respuesta a esta pregunta no puede ser sino negativa, por las razones pragmáticas bien defendidas, entre otros, por Manuel ATIENZA: una ciencia jurídica atenta en mantener su propia pureza virginal (la mayor parte de las veces sólo presunta) y que se retraiga en contribuir a la función del derecho de ofrecer razones para la acción, se condena a la irrelevancia práctica ${ }^{20}$. Utilizando las palabras de Mario JoRI (que sigue las enseñanzas de su maestro Uberto SCARPELLI), «el derecho como mecanismo normativo existe en la medida en que consigue dirigir o controlar los comportamientos y la teoría del derecho contribuye en esta tarea» ${ }^{21}$. Utilizando una metáfora evocativa, ideada siempre por JORI, se puede sostener que «hacer jurisprudencia no es como observar un bloque de mármol, sino que es como cantar en un coro [...], para que el coro exista es necesario que todos o casi todos los miembros del coro canten en dicho coro» ${ }^{22}$.

La perspectiva que la ciencia jurídica debe adoptar es al mismo tiempo cognoscitiva y normativa: es cognoscitiva porque no se puede prescindir de la práctica jurídica existente; y es normativa porque al ofrecer reconstrucciones y justificaciones de dicha práctica contribuye a modelarla ${ }^{23}$.

Sostener el carácter pragmático e «interno» del conocimiento jurídico no impone que se tenga que desacreditar cualquier otro punto de vista sobre el derecho. Aquí he adelantado algunos argumentos en contra de una ciencia jurídica que pretenda mantener las distancias con el propio objeto de estudio ${ }^{24}$.

Existen todavía otros puntos de vista sobre el derecho, pudiéndose calificar éstos como externos, que tienen una importancia innegable. En particular, me refiero a aquellas aproximaciones que adoptan la práctica de la sospecha como un método filosófico apropiado. Una perspectiva de este tipo expresó, por ejemplo, Franz KAFKA en la narración Sobre la cuestión de las leyes. KAFKA imagina un pueblo gobernado por un grupo de nobles a través de leyes que conocen únicamente el reducido círculo de nobles que detentan el poder. En un cierto momento, en esta narración se vislumbra la posibilidad no sólo de que el pueblo desconozca las leyes sino, además, que éstas no existan o, si existen, que coincidan con las decisiones arbitrarias de la nobleza («ley es aquello que hace la nobleza» $)^{25}$.

20 AtiEnZA, 2012. Allí el autor defiende también otras tesis —en particular el objetivismo ético- que no comparto pero que son relevantes en esta sede. Sobre la relevancia práctica de la ciencia jurídica, vid. también el apartado 7.

21 JORI, 2010: 15-16.

22 JoRI, 1997: 26. Vid. también CHIASSONI, 2005: 83-87.

23 Vid. también MACCORMICK, 2001: 24-30. Esta idea presenta una serie de analogías, en las que en esta sede no profundizaré, con la tesis de que la ciencia jurídica debe ser reconducida a la categoría del conocimiento práctico. Vid. Viola y ZaCCARIA, 1999: 33-37; CANALE, 2003: 132-160; TuZET, 2005.

24 Esta posición la mantiene, por ejemplo, sin demora Riccardo GUASTINI: «precisamente como el movimiento de los planetas no se confunde con un libro de astronomía, también una ley o un código se consideran distintos a un manual de derecho» (GUASTINI, 2011b: 440).

25 KAFKA, 1970: 403-405. La posibilidad vislumbrada por KAFKA puede ser reconducida al iusrealismo radical. Vid. POGGI, 2008: 57-65. 
El objetivo de aproximaciones de este tipo es precisamente el de vislumbrar la sospecha de que la realidad sea diferente a como parece. El arquetipo de una aproximación de este tipo es TRASIMACO que afirma que «la justicia es [...] el interés del más fuerte...». El mérito de la tesis de TRASIMACO es el de mostrar la diferencia entre la apariencia y la realidad. La apariencia es que toda propuesta de justicia es universal y, por tanto, vale para todos aquellos que se encuentren en su ámbito de aplicación; la realidad es que la justicia concierne sólo a los más fuertes y a la tutela de su interés. Sin embargo, el aspecto más interesante de la tesis de TRASIMACO no es la «realidad», verdadera o presunta, que ésta nos comunica, sino el hecho de haber avanzado la sospecha de que aquello que parece no se corresponde necesariamente con lo que es ${ }^{26}$.

Limitándose a citar algunos ejemplos ilustres, se puede señalar la idea de Karl MARX de que el derecho sea una superestructura se puede interpretar de esta forma; así como de esta manera se puede interpretar la hipótesis de Michel FOUCAULT de que la concepción ilustrada de las penas tutele sólo aparentemente valores como la libertad y la dignidad, mientras que en realidad sea un aparato conceptual capaz de hacer que las penas sean más eficaces a la hora evitar los comportamientos ilícitos respecto a los crueles suplicios del derecho premoderno; además, la lectura psicoanalítica de la práctica jurídica como sustituta de la figura paterna, propuesta por el realista americano Jerome FrANK, puede adscribirse a buen seguro a la filosofía de la duda; finalmente, lo mismo se puede decir de la hipótesis de Anders Vilhelm LUNDSTEDT de que el derecho funciona como una máquina que es capaz de producir reflejos pavlovianos en aquellos a los que afecta.

Las aproximaciones de este tipo sostienen que la práctica jurídica es distinta a cómo se presenta y de cómo aquellos que participan en la misma sostienen que sea. La actitud de sospecha es importante y debe fomentarse ( $;$ con la condición de que no se transforme en una paranoia!) a fin de mantener una actitud crítica y de control del derecho y del poder. No obstante, esta aproximación presupone necesariamente la existencia de participantes convencidos y de una ciencia jurídica que se tome en serio la perspectiva de los participantes. Si, hipotéticamente, los participantes se convenciesen en masa de que el derecho no funciona como ellos piensan que funciona, el resultado sería el fin del derecho como una práctica capaz de producir razones justificativas de la acción y, quizás, el fin del derecho tout-court. Una ciencia jurídica «externa» que practique la sospecha puede existir sólo «sobre los hombros» de una ciencia jurídica que está «al lado» de los participantes.

\section{CIENCIA JURÍDICA EN SENTIDO AMPLIO Y ESTRICTO}

Alguien se habrá percatado (con irritación creciente) que hasta el momento las locuciones «ciencia jurídica», «conocimiento jurídico»y otros términos parecidos se han empleado de una forma desenvuelta e intercambiable; además, el significado de dichas locuciones se ha dado por supuesto y no se ha mostrado ninguna preocu-

26 Vid. Platón, 1998: 338d-339a, 63. Habiendo recogido esta interpretación de las tesis del Trasimaco de Platón de IACONO, 2003. 
pación en proponer definiciones aunque sean puntuales. Ha llegado el momento de justificar algunas de estas decisiones y eliminar algunos defectos del análisis precedente.

En primer lugar, he empleado «ciencia jurídica» y «conocimiento jurídico» como sinónimos debido a una precisa elección que, a la vista de los párrafos precedentes, no debería sorprender. Preguntarse si la conciencia jurídica sea una verdadera ciencia (y, en su caso, bajo qué condiciones) es, quizás, una cuestión interesante sólo si se mantiene en el ámbito de la epistemología empirista (ingenua) y si se considera el monismo metodológico un dogma imprescindible. También en este último caso, no obstante, la sospecha de que se trate de una cuestión delicada es difícil de alejar. Tal sospecha se refuerza por el hecho de que el mismo BовBIO reconoce que el problema del carácter científico de la jurisprudencia es «más verbal que real» ${ }^{27}$. En definitiva, la pregunta interesante es: «¿cómo funciona (cómo debe funcionar) la ciencia jurídica?» y no «¿es el conocimiento jurídico una verdadera ciencia?».

En segundo lugar, he entendido el término «conocimiento jurídico» en su acepción más amplia posible, que comprende todas aquellas actividades que se presentan, con diversas denominaciones, como reconstrucciones del derecho. Una definición tan genérica, no impide que se puedan realizar algunas distinciones dentro del conocimiento jurídico; en especial, una diferenciación oportuna es la que distingue por un lado, entre «teoría del derecho» y «dogmática» o «doctrina» por el otro.

La teoría del derecho incluye las investigaciones sobre el derecho que no se refieren a un específico derecho positivo y a un determinado ordenamiento jurídico sino a una pluralidad de ordenamientos (en algunos casos, las investigaciones teóricas sobre el derecho se sitúan a un nivel tal de generalidad que incluyen a todos los sistemas jurídicos). Los discursos teóricos sobre el derecho «están dirigidos a formular una serie de nociones que se presumen comunes en varios ordenamientos [...]. Al realizar esto los teóricos del derecho [...] se preocupan por reconstruir también la compleja actividad (de los legisladores, juristas, operadores, etc.), desarrollada sobre una base prevalentemente lingüística, a través de la cual las nociones en cuestión vienen, según los casos, creadas, interpretadas, usadas, aplicadas en las distintas esferas en las que se articulan las prácticas jurídicas realizadas por estos sujetos, y en los distintos conceptos institucionales que en cada ocasión se toman como referencia» ${ }^{28}$.

La dogmática, en cambio, agrupa todos los discursos «de aquellos que se ocupan de investigar, por motivos "científicos", el contenido de sectores concretos de un determinado ordenamiento jurídico positivo» ${ }^{29}$.

Esta distinción no implica que existan diferencias cualitativas entre teoría del derecho y dogmática, ni que sea posible trazar líneas netas de separación entre estas. Por esta razón considero que sea plausible un discurso sobre la ciencia jurídica que ponga entre paréntesis las diferencias - por muchos aspectos interesantes y que no se deben subestimar- entre los distintos niveles en los que se articula la ciencia jurídica.

27 BовBIO, 1997: 134.

28 VILLA, 2013: 376-377, la cursiva aparece en el original.

29 Ibid., 376. 
El planteamiento de la tradición iusanalítica ortodoxa es bastante diferente ${ }^{30}$. Tal y como se indicaba en el primer párrafo, desde esta perspectiva tanto la ciencia jurídica como el derecho son discursos, pero discursos bien distintos. El derecho es un conjunto de normas (esto sirve evidentemente también para una perspectiva iusrealista moderada a la genovesa), por tanto se trata de un discurso compuesto prevalentemente por enunciados que tienen una función prescriptiva. La ciencia jurídica es un metalenguaje descriptivo que tiene por objeto el lenguaje prescriptivo del derecho. La ciencia jurídica expresa (debe expresar) proposiciones concerniente al derecho. A estos dos niveles de lenguaje es oportuno sobreponer un tercero, que es el de la epistemología jurídica la cual, teniendo por objeto la ciencia jurídica, se puede describir como un meta-metalenguaje. Según este planteamiento, la metajurisprudencia es prescriptiva, en el sentido que prescribe a la jurisprudencia que describa. Esta conclusión señala una distancia problemática (para quien mantiene esta perspectiva) entre la epistemología jurídica y la epistemología de las ciencias naturales. Esta última de hecho se limita a describir cómo las ciencias producen conocimiento. La epistemología jurídica no describe lo que hacen los juristas, sino que les dice lo que deberían hacer (y que generalmente no hacen). Esta disformidad se puede explicar observando que ««la meta-ciencia no puede describir el mundo en el que la ciencia jurídica produce el conocimiento sobre el derecho si el discurso sobre el derecho se presenta a sí mismo como un conjunto de conocimientos. No se puede hacer metaciencia sino sobre un discurso que tenga el carácter de ciencia. A fin de cuentas, no es que la epistemología jurídica de verdad prescriba el describir: lo que ésta hace es indicar las características que una ciencia del derecho debería tener si estuviera construida sobre la base de un modelo inspirado en aquel de las ciencias naturales» ${ }^{31}$.

El problema — que nadie niega - es que el discurso jurídico está parcialmente indeterminado. Esto implica que la mayoría de las veces a partir de una disposición es posible derivar más normas. Con la finalidad de mantener la distinción entre el derecho (lenguaje objeto) y la ciencia jurídica (metalenguaje), esta última debe ocuparse a) de «interpretación cognitiva», es decir de registrar todas las normas posibles que se pueden derivar de una disposición y b) de identificar y describir la «interpretación vigente» de una disposición (en el caso de que exista).

A la luz de este planteamiento, buena parte de aquello que efectivamente hacen los juristas (en particular la doctrina), en efecto, no puede considerarse un metalenguaje respecto al derecho sino que es parte del lenguaje del derecho. La doctrina, más que describir el derecho, lo modela, bien sea eligiendo una entre las posibles normas que se pueden extraer de una disposición por la vía interpretativa, bien sea produciendo nuevas normas que no están expresadas. Por esta razón, cuando el jurista realiza esta actividad (por ejemplo interpretación decisoria y formulación de nuevas normas), actividades consideradas por todos legítimas ${ }^{32}$, no se sitúa en el nivel metalingüístico sino en el nivel del lenguaje objeto.

30 Sigo en este punto a GUASTINI, 2011b: 439-450. Vid. también Guastini, 2011c: 213-225. Para una reconstrucción en clave crítica de esta perspectiva, vid. VILLA, 2012: 43-73.

31 TROPER, 2003: 25-26.

32 Giovanni Tarello, 1974: 376 por ejemplo observa: «es demasiado obvio que cualquier discurso de un jurista no escapa de la siguiente alternativa: o es absolutamente inútil, o está destinado a (viene destinado por 
En conclusión, la mayor parte de aquello que realizan los juristas no se puede reconducir a la ciencia jurídica, a menos que esta última no se entienda en sentido lato: la «verdadera» ciencia jurídica es aquella que describe el derecho. A este respecto me parece apropiada la observación de Giorgio PINO de que con frecuencia las oposiciones dicotómicas —en este caso específica aquella entre ciencia jurídica y doctrina«no son del todo inocentes, valorativamente neutras. [...] A menudo, construida una dicotomía, se la convierte tácitamente en una jerarquía. Uno de los entes diferenciados de la dicotomía "está por encima", es bueno, el otro "está por debajo", y es una mala copia» ${ }^{33}$.

Es evidente - y lo era ya antes- que la concepción de la ciencia jurídica que defiendo es alternativa respecto a la concepción iusanalítica «ortodoxa» que aquí he reconstruido. El punto que me interesa subrayar como conclusión de este apartado, sin embargo, no es esta divergencia, sino el hecho de que la epistemología jurídica analítica rechaza considerar como ciencia jurídica (en un sentido lato) algunas actividades que casi todos reconocen como i) casos paradigmáticos de la ciencia jurídica. Éste no es un argumento decisivo contra esta concepción (demasiado) exigente de la ciencia jurídica, pero es ciertamente un punto a favor de un modelo más amplio y articulado. Parafraseando a HART, un modelo de ciencia jurídica simple y que suministre seguridad no se puede obtener pagando el precio de una distorsión de la realidad.

\section{5. «EL GIRO INTERPRETATIVO»Y CIENCIA JURÍDICA INTERPRETATIVA: ACLARACIONES PRELIMINARES}

¿Cuáles son las características de una ciencia jurídica interpretativa?

Para responder a esta pregunta es necesario en primer lugar rechazar las lecturas banales, simplistas, confusas y equivocadas del «giro interpretativo» que utilizan como una especie de eslogan la célebre observación de DwORKIN de que «la práctica legal, a diferencia de muchos otros fenómenos sociales, es argumentativa» ${ }^{34}$.

Además, es necesario explicitar las características del «giro interpretativo» que no se discutirán en este artículo porque se refieren a cuestiones inherentes a la ontología del derecho (por consiguiente, relativas a la pregunta: «¿qué es el derecho?») más que a cuestiones epistemológicas en un sentido amplio (y, por tanto a la pregunta: «¿Cómo se conoce el derecho?»).

En definitiva, en este apartado se realiza una enumeración de algunos aspectos del «giro interpretativo», de los cuales, por diferentes razones, no considero necesario tratar en esta sede.

La tesis de que la ciencia jurídica sea interpretativa está sin duda ligada a la naturaleza interpretativa o argumentativa de la praxis jurídica; esta última tesis, como he

el autor y objetivamente "tiene el destino de") asumir "fuerza" preceptiva o directiva (frente a sus homólogos, o también frente a los jueces, y habitualmente también frente a otros juristas)».

33 PINO, 2013: 80.

34 DWORKIN, 1988: 23. Para una presentación exhaustiva de una perspectiva iusfilosófica, vid. STAVROPOULOS, 2003. 
señalado, se presta a ser banalizada o malentendida y, por tanto, es oportuno intentar clarificarla.

En una acepción verdaderamente banal, afirmar que el derecho es interpretación significa sostener que la actividad interpretativa es una característica que pertenece a la práctica jurídica. Los juristas, en definitiva, generalmente interpretan. Nadie lo niega: es una afirmación verdadera, y por tanto, obvia y excesivamente genérica. ¿№ se podría decir lo mismo, por ejemplo, de la literatura y de las artes en general? ¿La actividad principal de los críticos no es tal vez interpretar? Queriendo exagerar, también el fútbol podría ser considerado como una práctica interpretativa, al menos a juzgar por las interminables discusiones, en los periódicos y en la televisión, sobre las decisiones arbitrales. Si se entiende de esta forma, la tesis del derecho como práctica social interpretativa más que marcar un giro se preocupa por rebatir lo obvio.

En una acepción un poco más densa pero equivocada, el «giro interpretativo» se utiliza contra el positivismo jurídico. Un ejemplo de este uso del «giro interpretativo» viene representado por las siguientes observaciones de Gustavo ZAGREBELSKY, extraídas de su afortunado libro El derecho dúctil: «Según la concepción positivista tradicional, en la aplicación del derecho la regla jurídica se obtiene teniendo en cuenta exclusivamente las exigencias del derecho. [...] Como, además, una vez determinada la regla, su aplicación concreta se reducía a un mecanismo lógico sin discrecionalidad [...] se comprende que los problemas de aplicación del derecho viniesen íntegramente absorbidos en los de la interpretación»; para una concepción interpretativa del derecho, en cambio, «el caso es el motor que impulsa el intérprete y marca la dirección. Partiendo del caso se acude al derecho para interrogarlo y obtener de él una respuesta. A partir del caso, el intérprete procede a buscar las reglas y vuelve a él, en un procedimiento circular (el denominado "círculo interpretativo") de dirección bipolar que finaliza cuando se componen de modo satisfactorio las exigencias del caso y las pretensiones de las reglas jurídicas» ${ }^{35}$. En este caso, una pretensión estereotipada del positivismo jurídico (que, en la mejor de las hipótesis, puede considerarse adecuada en relación con el positivismo jurídico del siglo XIX) se acompaña de una concepción del derecho que pretende convertirse en una alternativa respecto al positivismo jurídico pero que, a este nivel de generalidad, es difícil considerar como tal.

Un modo más sofisticado de contraponer el «giro interpretativo» al positivismo jurídico consiste en poner de manifiesto que la imagen iuspositivista del derecho como un sistema de reglas (el «modelo de las reglas» que DwORKIN atribuye a HART) no es correcta y que el rol crucial de los principios convierte al derecho inseparable de la moral. También en este caso, el positivismo jurídico puede responder con argumentos convincentes, pero sobre los cuales aquí no nos podemos detener.

La versión más interesante del «giro interpretativo» en clave anti-iuspositivista coincide con la concepción del derecho como integridad. Esta propone una imagen del derecho como una práctica social construida alrededor de principios y valores (que pueden/deben ser entendidos como) incongruentes. El derecho coincide por tanto con aquella interpretación de la práctica que por encima de las otras es capaz de considerar el valor de la integridad. Siguiendo de una forma libre la reconstrucción que

35 ZagrebeLSKY, 1995: 131-132 y 133-134. Vid. también ZagrebelsKY, 2003: 621-650. 
realiza RAZ ${ }^{36}$, para DWORKIN el derecho coincide con la mejor reconstrucción moral de la práctica jurídica que, precisamente, consiste en reconocer el carácter central que ocupa el valor de la integridad. Este planteamiento representa una alternativa, tanto frente al denominado positivismo jurídico exclusivo, según el cual «todo el derecho es un producto de alguna fuente», como frente al denominado positivismo jurídico inclusivo, según el cual «todo el derecho o es producto de alguna fuente o está reconocido por el derecho producido por alguna fuente». La concepción del derecho como integridad se merece ser tomada seriamente en consideración y, en cierta medida, presupone la idea de una ciencia jurídica interpretativa. Como se ha anticipado, sin embargo, en esta sede me interesa mostrar por qué la ciencia jurídica es (debe ser) interpretativa y no comparar las distintas respuestas a la pregunta «¿qué es el derecho?» propuestas por una ciencia jurídica interpretativa. Por este motivo evitaré profundizar en el discurso de la concepción del derecho como integridad.

Finalmente, la idea de que el derecho sea interpretación expresa también una concepción precisa de la interpretación jurídica que es posible denominar neoformalismo interpretativo y cuya versión más célebre es la tesis dworkiniana de «la única respuesta justa». Esta tesis implica que se atribuya, como ya se ha dicho, un papel crucial a los principios, que se admita alguna versión del objetivismo ético y se minimice la discrecionalidad interpretativa. Ésta es una tesis que indudablemente ha tenido un fuerte impacto sobre la representación de los jueves y de los juristas sobre su propio papel, pero que también presenta muchos límites y puntos oscuros; en cualquier caso, también se trata de un aspecto del «giro interpretativo» del que se puede prescindir.

\section{EN DEFENSA DE UNA CIENCIA JURÍDICA INTERPRETATIVA}

A fin de determinar cuáles sean las características de una ciencia jurídica interpretativa es útil retomar y profundizar en las reflexiones precedentes sobre la influencia que el objeto de estudio - el derecho, en nuestro caso- - y las características específicas tienen en la actividad cognoscitiva ( $v i d$. el apdo. 3). La naturaleza interpretativa de la ciencia jurídica depende de hecho de las características del concepto de derecho. A este respecto considero útil retomar la distinción propuesta por DWORKIN entre tres tipos de concepto ${ }^{37}$.

Algunos conceptos son criteriales en cuanto que presuponen un acuerdo generalizado sobre una definición, que puede ser precisa o aproximativa, la cual permita distinguir entre usos correctos y usos incorrectos. «Equilateralidad» es un concepto criterial absolutamente preciso, «soltero» es razonablemente preciso aunque si existen usos dudosos de este concepto (por ejemplo: ¿tiene sentido decir que un niño de cinco años es soltero?); «matrimonio» es un concepto criterial todavía más impreciso (¿una unión entre personas del mismo sexo es un matrimonio?) ${ }^{38}$. Una cuestión interesante,

36 RAZ, 2005a: 286-315.

37 Vid. DwORKIN, 2010: 3-40 y 153-203 y DwORKIN, 2013: 183-217.

38 Todos los ejemplos están extraídos de DwORKIN, 2010 y 2013. Según Raz, 2001: 1-37 y STAVROPOULOS, 2001: 59-97, HART considera «derecho» un concepto criterial. RAZ comparte esta tesis de HART, mientras STAVROPOULOS sostiene que tenga razón DWORKIN cuando sostiene que «derecho» es un concepto interpretativo (infra). 
que aquí no podemos afrontar, es la de establecer cuánta imprecisión puede soportar un concepto criterial antes de transformarse en un concepto de otro tipo (y, es precisamente, en un concepto interpretativo). Se puede decir, de todas formas, que un concepto, para ser tratado como criterial, debe garantizar una amplia «zona clara» de aplicaciones no controvertidas.

Otros conceptos son de «tipos o géneros naturales»: «los tipos naturales son cosas que tienen una identidad fija en la naturaleza, como un compuesto químico o una especie animal, y $[. .$.$] las personas comparten un concepto de tipo natural cuando$ lo usan para referirse a un mismo tipo natural» ${ }^{39}$. Se trata de conceptos de los cuales presuponemos que exista una «esencia natural» (la composición molecular, el ADN, etc.) que no depende de los criterios que nosotros empleamos habitualmente para identificar las instancias de uso correctas de tales conceptos. Por ejemplo, yo puedo estar convencido (y los seres humanos en general habrán estado convencidos durante mucho tiempo) que el leopardo y la pantera son dos especies animales diferentes: en el momento en el que descubro que su ADN es el mismo, tendré que modificar mis convicciones. En Moby Dick, Ismael se rebela contra Linneo, que separa las ballenas de los peces: «siendo aquí conocido que, absteniéndome de cualquier argumentación, sostengo siguiendo la buena moda antigua el punto de vista que la ballena es un pez, y pido auxilio al santo Giona para que me ayude» («Be it known that, waiving all argument, I take the good old fashioned ground that the whale is a fish, and call upon boly Jonah to back me») ${ }^{40}$. También en este caso, no es oportuno abrir un debate entre los que apoyan por una parte a Linneo y aquellos que lo hacen a Giona e Ismael por el otro: la ballena no es un pez y no lo era tampoco en el tiempo de Giona.

Por final, algunos conceptos son interpretativos. Se trata de conceptos que a) están relacionados con prácticas sociales, $b$ ) expresan el valor o los valores en relación con el cual o con los cuales determinadas prácticas se han construido y $c$ ) soportan «diferencias de opinión fuertes y completamente irreducibles sobre casos particulares» ${ }^{41}$.

El modo en el que DwORKIN describe los conceptos interpretativos se puede reconducir claramente al análisis de los «conceptos esencialmente contestables» propuesta por Walter B. GALLIE ${ }^{42}$; sin caer en análisis exegéticos del pensamiento dworkianiano, me parece oportuno observar al menos que, aunque sin saltos o cambios radicales, la concepción interpretativa del derecho propuesta por DwORKIN ha adquirido poco a poco contornos más claros y, sobre todo en relación con las características del derecho como concepto interpretativo, la deuda de DwORKIN frente a GALLIE emerge con una claridad siempre mayor.

Por esta razón, presentar la noción de concepto esencialmente contestable resulta útil para hacerse una idea más clara de qué entiende DwORKIN por concepto inter-

39 DWORKIN, 2013: 185. Para decirlo con las palabras Hilary PUTNAM, 1987: 266: «si existe una estructura escondida, ésta generalmente determina en qué cosa consiste el ser miembro del género natural, no sólo en el mundo real, sino en todos los mundos posibles. En otros términos aquello que nosotros podemos y no podemos suponer en términos fácticos sobre el género natural (“¿el agua podría haber sido toda vapor?”, sí: “¿el agua habría poder sido XYZ?”, no)».

40 Melville, 1992: 136.

41 DWORKIN, 2013: 187.

42 Gallie, 1956: 167-198; Vid. Guest, 1992: 34-37. 
pretativo. Los conceptos esencialmente contestables presentan cinco características ${ }^{43}$ : 1) son conceptos que explicitan el valor (appraisive) de una acción considerada como digna de ser perseguida y que conectan entre ellos de modo indisoluble la acción y el valor que en ésta subyace; 2) la acción sobre la cual un concepto contestable explicita el valor debe ser compleja y articulada; 3 ) las reconstrucciones de tales conceptos deben tener en consideración todos los distintos aspectos y las diversas características de la acción; 4) la acción sobre la que el concepto contestable explicita el valor debe tener un carácter «abierto», debe por tanto ser capaz de soportar cambios significativos, no previsibles con antelación; 5) el uso de los conceptos esencialmente contestables presupone el conocimiento sobre la existencia de usos alternativos con los cuales el uso elegido debe contrastarse y respecto de los cuales debe esforzarse por prevalecer: «to use an essentially contested concept means to use it both aggressively and defensively ${ }^{44}$. $\mathrm{Si}$ el derecho es un concepto interpretativo - $\mathrm{y}$ a mí me parece difícil negarlo- es necesario resignarse a admitir que también la ciencia jurídica es (en el sentido de que no puede sino ser) interpretativa.

Como hemos visto (vid. el apdo. 4), la ciencia jurídica se ocupa del derecho desde diversas perspectivas y diversas «distancias». En primer lugar, la teoría y la filosofía del derecho ${ }^{45}$ están llamadas a responder a la pregunta «¿Qué es el derecho?». Como señala agudamente HART, las respuestas a esta preguntan han sido múltiples y muy distintas entre ellas (vid. el apdo.3). Éste es el indicio principal para respaldar la naturaleza interpretativa o esencialmente contestable del concepto de derecho. El concepto de derecho se refiere a una práctica social dotada de valor. En este sentido, es difícil negar que exista una conexión necesaria entre derecho y moral. Una conexión necesaria de este tipo ha sido reconocida por muchos autores y, hay que decir de paso, no incide en la contraposición entre iusnaturalismo y iuspositivismo. HART habla de «contenido mínimo del derecho natural» y, sobre todo, identifica un nexo inescindible entre derecho y justicia (que define «la virtud más jurídica»); Carlos NINO observa que el concepto de derecho tiene asociado un significado emotivo favorable, Robert ALEXY y Neil MACCORMICK señalan como una característica esencial del derecho sea la de adelantar una pretensión de corrección; RAZ construye su versión del positivismo jurídico a partir de su concepción de la autoridad y del presupuesto de que el derecho no puede no avanzar la pretensión de ser una autoridad legítima y así se podría seguir.

Cada definición de derecho representa un intento — consciente o inconscientede ofrecer una reconstrucción de la praxis jurídica a la luz del valor que en esta subyace, valor que, genéricamente, podemos reconducir, siguiendo a DWORKIN, al principio de legalidad. Optar por una concepción del derecho en lugar de por otra, tienen sus consecuencias, pero también incide profundamente en la doctrina ${ }^{46}$ que, a su vez, incidirá de forma directa en la praxis jurídica.

43 Aunque Gallie distinga siete características de los conceptos esencialmente contestables, en esta sede es posible omitir las últimas dos. Vid. en su caso GALLIE, 1956: 171-180.

44 Gallie, 1956: 172.

45 Si se acepta la tesis que el derecho sea un concepto interpretativo o esencialmente contestable, es necesario renunciar a trazar límites netos entre la teoría y la filosofía del derecho. DwORKIN, 2010, en relación con las reflexiones sobre el derecho de este tipo utiliza la expresión jurisprudential stage.

46 DwORKIN, 2010 usa la expresión doctrinal stage. 
El funcionamiento de una ciencia jurídica interpretativa es entendido perfectamente por JORI ${ }^{47}$. Sobre este punto, es posible destacar una cierta consonancia entre las tesis de DwORKIN y las de JORI ${ }^{48}$. Las diferentes concepciones del derecho - que JORI denomina, con un inglesismo, «concepciones idiosincrásicas»- presuponen la existencia de un concepto de derecho de sentido común con sus contornos borrosos pero, no obstante eso, suficientemente precisos para permitir que se pueda distinguir el silbato del jefe de la estación que ordena la salida de los trenes de los gestos del loco que, después de que el jefe de la estación ha silbado, mueve los brazos y, también él, parece que ordene salir a los trenes ${ }^{49}$. Afirma JorI: «Que aunque diferenciándose parcialmente del concepto de derecho del sentido común, las concepciones idiosincráticas del derecho no violan [...] el consenso mínimo sobre qué es el derecho, la base necesaria para la existencia en la sociedad de la práctica colectiva e institucional del derecho, el presupuesto indispensable del discurso y de la práctica de los jueces, aquel instrumento común que permite que se entiendan los técnicos y los profanos cuando miran alrededor para ver qué es el derecho en una sociedad, por lo que todos se encuentran mirando más o menos en la misma dirección, en la dirección en la que después, en una sociedad normal, se encuentran los ordenamientos jurídicos históricos con sus reglas de autodeterminación $»^{50}$.

La posibilidad de distinguir con claridad a un jefe de estación de un loco es prueba de la existencia de una práctica jurídica compartida. El sentido común delimita, ante todo, el derecho vigente aquí y ahora y, a partir de este derecho, delimita las características del derecho en general, características que, en opinión de JORI, son la coercitividad (en primer lugar), la institucionalización y la normatividad. Incidentalmente, considero que JORI se equivoca al no introducir entre las características del derecho de sentido común la representación del derecho como una práctica social que adelante la pretensión de emanar normas justas y, por tanto, considero que se equivoca cuando afirma que «la justicia [está] presente en el pensamiento común más bien como carácter negativo del derecho, es decir como un elemento que el sentido común considera que desgraciadamente a menudo falta en el derecho sin que este cese por ello de ser tal, según el sentido común» ${ }^{51}$.

En cualquier caso, el concepto derecho de sentido común dicta las coordinadas dentro de las cuales la ciencia jurídica tiene liberta de movimiento. JoRI expresa esta idea a través de una metáfora convincente: «el jurista sabe moverse perfectamente

47 Me refiere en particular a JORI, 2010.

48 Es con un cierto sadismo que destaco esta asonancia, conociendo bien la aversión de Mario JoRI por DwORKIN. Debo decir de todas formas que se trata de una asonancia de la que JORI no es consciente. Vid. JORI, 2010: 131, n. 169.

49 Vid. la reconstrucción crítica de las tesis de JORI propuesta por COMANDUCCI, 2012. Una interesante discusión crítica de JORI, 2010 se encuentra en Diritto E questioni pubbliche, 11, 2011, con artículos de DiCIOTti, Fuselli, Ruiz Manero, Villa.

50 JORI, 2010: 84.

51 Ibid.: 31-32, cursiva en el original. Una objeción parecida la adelantó DiciotTi, 2011: 965-972. Es precisamente el hecho de que el derecho avance necesariamente una pretensión de corrección lo que frustra los intentos de encontrar una vía intermedia entre las teorías del derecho descriptivas y las teorías del derecho valorativas. El intento más tozudo — en el que no profundizaré- de proponer una vía media es probablemente es de Julie Dickson. Vid. Dickson, 2001 y Dickson, 2004: 117-156. Para una reconstrucción crítica de la propuesta de DiCKSON, vid. BuRAZIN, 2012: 182-210. 
dentro de su manzana, de su derecho; pero no sabe llegar; para ejercitar su conocimiento debe estar ya alli ${ }^{52}$. Forzando una conocida metáfora de DwORKIN, se podría representar el derecho de sentido común como el tronco de un árbol mientras que las concepciones idiosincráticas serían las ramas de este árbol ${ }^{53}$.

La conexión entre conocimiento de sentido común y conocimiento científico, bien puesto en evidencia por JORI, marca una importante diferencia entre la ciencia jurídica y las ciencias naturales (vid. el apdo. 3); además, permite comprender cuáles sean los vínculos de la ciencia jurídica. Si es verdad, por una parte, que la ciencia jurídica es interpretativa, en el sentido que propone reconstrucciones alternativas y en conflicto del derecho, por otra el sentido común permite distinguir entre determinaciones admisibles y determinaciones inadmisibles del derecho ${ }^{54}$. Obviamente, y lo repito (vid. el apdo. 3), mantener esto no impone prohibir reconstrucciones del derecho de «segundo nivel», basadas en la sospecha de que aquello que parece no es. Bien se puede mantener que el gusano, más que en una manzana, se encuentra dentro de una trampa para matar a los gusanos. Sin embargo, si tales reconstrucciones vienen aceptadas in toto y no sólo como un estímulo para mantener una actitud crítica y circunspecta frente al derecho el único resultado posible es la disolución del derecho todavía antes que la ciencia jurídica. En El Show de Truman, cuando Truman Burbank es consciente de que es el protagonista de un espectáculo televisivo no puede hacer otra cosa que abrir la puerta del plató cinematográfico, inclinarse para recibir sarcásticamente los aplausos del director y de todo el público, y salir de la escena.

La relación entre el conocimiento de sentido común y el conocimiento científico es compleja. El sentido común pone límites a la ciencia jurídica, también, a largo plazo, la ciencia jurídica modifica el sentido común del derecho y esto produce cambios en la práctica jurídica y, de ahí, también en la ciencia jurídica y así sucesivamente. Empleando la metáfora del gusano y la manzana, se podría decir que la «manzana» dentro de la cual se mueve el jurista como un gusano no es siempre la misma y que, si la situación es propicia, el gusano puede hacer algo para pasar de una manzana a

52 JORI, 2010: 53, la cursiva está en el texto original. Vid. ANDRONICO, 2012: 16-17. Una tesis parecida se defiende también en DiciotTI, 2007: 38: «[...] el derecho parece funcionar como especie de ideología de la cual depende la unidad del grupo, una ideología que tolera en cierta medida las divergencias que pueden surgir localmente sobre cuestiones concretas, pero no un desacuerdo sobre las palabras de orden fundamentales. El consenso sobre las palabras de orden fundamentales es de hecho una condición para la existencia de la propia ideología y, por tanto, también del grupo. El hecho de que el consenso sobre estas palabras —o, fuera de la metáfora, sobre los principios relativos a la validez y a la interpretación - sea un consenso sobre las palabras, al cual podría no corresponder un consenso sobre el significado preciso de estas palabras - fuera de la metáfora, un consenso sobre el contenido preciso de una regla de reconocimiento que indica los criterios para la identificación de las normas jurídicas válidas-, no es relevante, por qué los disensos latentes sobre el significado de estas palabras se manifiestan únicamente como disensos locales sobre cuestiones de concreta aplicación de la ideología. Así la ideología cumple su propia función, que es aquella de satisfacer las necesidades de reconocimiento y de cooperación: reconocerse en las mismas palabras de orden, discutir sobre la base de «los mismos» paradigmas y en el mismo lenguaje, trabajar en un proyecto «común». De esta forma la ideología absorbe las diferencias y los conflictos sociales, puesto que cada conflicto determinado por intereses individuales contrapuestos, cuando su expresión se confía al lenguaje de la ideología, se presenta como un contraste sobre el diverso modo de interpretar o aplicar localmente las palabras de orden compartidas».

53 DWORKIN, 1988: 60-61.

${ }^{54}$ Utilizo aquí el léxico introducido por JoRI, que utiliza la expresión «individuación del derecho» en relación con el concepto de derecho de sentido común y «determinaciones del derecho» en relación con las concepciones idiosincrásicas de la ciencia jurídica. 
otra ${ }^{55}$. La idea de derecho de sentido común de la época de la codificación es muy distinta de la idea de derecho de sentido común de la época de la constitucionalización. Al producirse este cambio un papel que no se puede dejar de lado se atribuye a la ciencia jurídica.

Esta reconstrucción de la relación articulada entre derecho, sentido común y ciencia jurídica nos permite dar un paso adelante respecto al apartado 3. No sólo una ciencia jurídica «pura» no es oportuna, en cuanto condenada a la irrelevancia, sino que es también imposible: «el método jurídico no se puede fundar sobre elecciones del todo científicas y puramente cognitivas [...]; por el contrario la descripción del derecho jurisprudencial resulta dirigida a la práctica e invariablemente determinada por elecciones de valores fuertes, es decir políticos. La neutralidad puede más bien ser perseguida en la forma de la intersubjetividad, haciéndose evidentes las elecciones de valores presupuestas, permitiendo a los interlocutores verlas y discutirlas» ${ }^{56}$.

Algunos ejemplos concretos pueden contribuir a corroborar esta conclusión.

GUASTINI sostiene que «la ciencia jurídica, propiamente entendida, es [...] una descripción a-valorativa del derecho: del derecho así como es» ${ }^{57}$. ¿Qué significa describir el derecho? Esta pregunta, reconoce GUASTINI, admite distintas respuestas según la concepción del derecho que adoptemos: si preferimos una concepción normativista, entonces la ciencia jurídica describirá normas; si por el contrario, optamos por el corte iusrealista el objeto de la ciencia jurídica serán las decisiones jurisdiccionales. ¿Una ciencia jurídica que selecciona el propio objeto de estudio puede ser considerada como descriptiva y a-valorativa? A mí me parece que no ${ }^{58}$. Y la respuesta es negativa siempre que se admita que exista una cierta superposición entre el normativismo y el realismo moderado y que el iusrealismo extremo sea una perspectiva insostenible (aunque sí, de hecho, ha tenido, y tiene, muchos autores que la apoyan también entre los juristas de prestigio).

Otro ejemplo se refiere a las «lagunas imaginarias» y a las «normas apócrifas» (también a la presunta homosexualidad de Oliver Twist). Dice siempre GuASTINI que el enunciado «Oliver Twist es homosexual» no es ni verdadero ni falso (como mucho, sin duda falso) porque Charles DickeNs no escribió nada (explícito) al respecto en su novela. Del mismo modo, el art. 87, apartado 5 de la Constitución. Que dispone: «[el Presidente de la República] promulga los decretos que tienen valor de ley» ha sido (y es) objeto de disputas «interpretativas» relativas a la determinación de los límites del Presidente de la República para dictar decretos. De hecho, «enunciados del tipo "el Presidente de la República no puede rechazar la promulgación de decretos ley sino en circunstancias determinadas" (circostanze cosi e cosi) $\gg^{59}$ no son ni verdaderas

55 La incidencia de la ciencia jurídica sobre el sentido común se ha reconocido, pero, en mi opinión, no se ha profundizado adecuadamente por JORI. Vid. JORI, 2010: 110.

56 JORI, 2010: 134. Es la elección ética de comprometerse a explicitar lo máximo posible las propias elecciones de valor lo que determina un salto profundo entre JORI (y SCARPELLI) por un lado y DwORKIN por el otro. En el debate anglosajón, una perspectiva de este tipo la defiende, entre otros, MACCORMICK, 1985: 1-41 y MurPHY, 2001: 371-409.

57 Guastini, 2011: 442.

58 A mí me parece, además, que las valoraciones requeridas al estudioso del derecho presenten inevitablemente implicaciones políticas y, en sentido lato, morales. Contra, DiCKSON, supra n. 50.

59 GUASTINI, 2011: 448-449. 
ni falsas (al máximo, sin duda falsas) o en cuanto enunciados interpretativos deben convertirse en formulaciones de una norma apócrifa. A pesar de no querer entrar en la cuestión, también en estos casos se presuponen toda una serie de opciones metainterpretativas, que tienen además evidentes implicaciones ideológicas y, en el caso del derecho, políticas en sentido estricto ${ }^{60}$. Además, si se quisiera seguir hasta el fondo este planteamiento, es necesario admitir que si, por ejemplo, una norma prohíbe dormir en las estaciones de tren, entonces el juez que absuelve al distinguido señor que se había dormido, sentado, esperando la llegada de su tren, está ignorando el derecho vigente; en cambio, si otro juez condena al vagabundo que se había acostado con un almohadón bajo la cabeza en un banco de la estación pero que todavía estaba despierto en el momento de la detención, este juez está usando como premisa mayor de su decisión una norma apócrifa ${ }^{61}$. Y esta no parece ser en absoluto una reconstrucción satisfactoria de la situación.

Pierluigi CHIASSONI, finalmente, a propósito de la contraposición entre el normativismo (a la HART) y el interpretacionismo (a la DWORKIN) observa: «la elección entre una u otra forma de verlo [...] sólo podrá depender, en conclusión, de la aceptación del fondo teórico de una u otra opción y de factores extrateóricos» ${ }^{62}$. Esta observación puede interpretarse como un anuncio (¿involuntario?) a favor una ciencia jurídica interpretativa o, en otros términos, como el reconocimiento de que, a nivel metateórico, DWORKIN tiene razón y los que apoyan una ciencia jurídica a valorativa y descriptiva (entre los cuales, también HART) se han equivocado.

\section{DOS MODELOS DE CIENCIA JURÍDICA}

Establecido que la ciencia jurídica únicamente puede ser interpretativa, es oportuno preguntarse cuáles son las características ulteriores de la ciencia jurídica de hoy y, quizás, del futuro inmediato. A este respecto, me contento con retomar algunas reflexiones de BоввіO sobre la ciencia jurídica que me parecen de largo alcance, aunque con frecuencia dejadas de lado (y con razón) cuando se reconstruye la concepción bobbiana de la ciencia jurídica ${ }^{63}$.

BoBBIO distingue entre dos modelos ideales y típicos de jurista.

El primer modelo representa al jurista como el «guardián» y el depositario de un cuerpo de reglas ya dadas. Según este primer modelo, añade BовBIO, la actividad principal del jurista es aquélla interpretativa. Hay que precisar que, para este modelo la actividad interpretativa prevé (o debe prever) un limitado o si es posible un nulo ejercicio de discrecionalidad por parte del intérprete. Este modelo, sea dicho de paso, está también detrás de la distinción neta entre derecho como lenguaje-objeto y la ciencia jurídica como metalenguaje. No hay que cometer el error de considerar este modelo como alternativo respecto a una ciencia jurídica interpretativa de la forma en la que se la ha caracterizado en el apartado anterior. La imagen del jurista guardián es el resulta-

\footnotetext{
60 Para una profundización, Vid. VILla, 2012: 43-73. Vid. también Barberis, 2001: 32-33.

61 El ejemplo se encuentra en Fuller, 2005: 161-168. Vid. también PinO, 2013: 81-88.

62 ChIASSONI, 2013: 78.

63 Vid. BоввIO, 2007: 34-47.
} 
do de elecciones ideológicas y políticas relativas, en general, a la forma de entender el principio de legalidad, la relación entre poderes, la autoridad del Estado, etc. Se trata, en buen derecho, de una concepción interpretativa de la ciencia jurídica que considera a esta última como subordinada al poder político. Significativas a este respecto son las palabras de Charles DemOLEDME: «Mi lema, mi profesión de fe es además: ;los textos por encima de todo! Yo publico un Curso del Código de Napoleón: mi objetivo es por tanto interpretar, explicar el propio Código de Napoleón, considerado como una ley vigente, como una ley aplicable y obligatoria, y mi preferencia por el método dogmático no me impedirá emplear como base los propios artículos de la ley» ${ }^{64}$.

El segundo modelo representa al jurista como «creador» del derecho: según este modelo, el jurista es con pleno título un participante en la praxis jurídica y contribuye a modificar, integrar y transformar el sistema jurídico de referencia. BOBBIO sostiene que la principal actividad del jurista según este modelo sería la investigación, la creación del derecho. Yo diría en su lugar que también en el caso en el que el jurista se represente (o venga representado) como creador del derecho, la actividad que lo caracteriza es siempre interpretativa. Aquello que cambia respecto al primer modelo es el comportamiento del jurista respecto a la interpretación. En el primer caso, el jurista adopta un comportamiento de autolimitación (self-restraint), mientras que en el segundo expande al máximo su propia discrecionalidad a través del recurso a los principios, las normas programáticas y a la interpretación constitucional orientada ${ }^{65}$.

Diversas son las variables que inciden a la hora de determinar la superioridad de un modelo sobre otro.

La primera variable está ligada al tipo de sistema jurídico en el que el jurista opera («variable institucional»). Un sistema jurídico puede ser cerrado o abierto. Será cerrado si está compuesto por un cuerpo sistemático de reglas que tienden a la plenitud, expresadas en un lenguaje determinado; será por el contrario abierto si las reglas son «fluidas;, es decir, indeterminadas y en continua transformación, y si «al jurista se le atribuye la función de colaborar junto con el legislador y con el juez en la tarea de creación del nuevo derecho» ${ }^{66}$.

La segunda variable depende de la situación social general («variable social»). Una sociedad puede ser estable o en transformación en función de la menor o mayor influencia de los factores de cambio sobre los modelos culturales existentes.

La última variable depende de la (o de las) concepción(es) del derecho predominante(s) entre los juristas y de la forma en la que se «calibra» la relación entre el derecho y la sociedad («variable cultural»). El derecho puede ser visto como un sistema autónomo y ampliamente autorreferencial o bien como un subsistema de un sistema global o como una superestructura de la estructura social y económica en particular. Es conveniente añadir que, en el caso en el que el derecho se considere como un subsistema del sistema social, resulta interesante profundizar en el papel del derecho dentro de la sociedad. Es interesante entender, en otras palabras, si el derecho se coloca en el centro o en los márgenes del sistema social.

\footnotetext{
64 Tomo esta cita de BoBBIO, 1996: 83, la cursiva está en el original.

65 Vid. GuASTINI, 2011b: 195-223.

66 BоввIO, 2007: 36.
} 
Bien, una vez visto que es difícil negar que el derecho en los países constitucionales sea un sistema abierto (diría «abierto de par en par»), que la sociedad (al menos la occidental), también como consecuencia de la globalización, esté en continua transformación y se caracteriza por el pluralismo y el multiculturalismo, que el derecho se entienda con mayor frecuencia como un reflejo y una variable dependiente de la sociedad $^{67}$, es evidente que el modelo de ciencia jurídica «ganador», aquí y ahora, es aquel que BoBBIO denomina creativo: «en esta perspectiva la actividad principal del jurista ya no es la interpretación del derecho ya creado sino la búsqueda de un derecho por hacer, in fieri, no tanto la convalidación según un análisis de las fuentes formales del derecho que es, cuanto la legitimación, en función de los principios materiales de justicia, del derecho que debe ser» ${ }^{68}$.

La predominancia del «jurista-creador» sobre el «jurista-guardián» contribuye a explicar, en un plano fáctico, la crisis de un modelo - como es el propuesto por la ortodoxia iusanalítica- de ciencia jurídica que tiende a la descripción y a la a-valoratividad y que pretende, aunque sin conseguirlo nunca del todo, mirar al derecho desde fuera. Adquirir la consciencia de que las reglas del juego han cambiado es un paso imprescindible tanto para quien quiera participar en el nuevo juego como para quien decida confirmar su fidelidad a las viejas reglas y/o combatir para que vuelvan a estar en vigor. Cualquiera que sea la opción a la que se tienda, se trata siempre de una práctica interpretativa en la que hay que comprometerse.

(Traducción de Lucía Aparicio Chofré)

\section{BIBLIOGRAFÍA}

ANDRONICO, A., 2012: Viaggio al termine del diritto. Saggio sulla governance, Torino: Giappichelli.

AtiEnZA, M., 2012: «Una teoria pragmatica del diritto», Rivista difilosofia del diritto, 1, 123-134.

BARBERIS, M., 2001: «Lo scetticismo immaginario. Nove obiezioni agli scettici à la génoise», en P. ComANDUCCI y R. GUASTinI (a cura di), Analisi e diritto 2000. Ricerche di giurisprudenza analitica, Torino: Giappichelli, 1-36.

Bоввіо, N., 1996: Il positivismo giuridico (1. ${ }^{a}$ ed. 1961), Torino: Giappichelli.

- 1997: Autobiografia, Roma-Bari: Laterza.

- 2007: Dalla struttura alla funzione. Nuovi studi di teoria del diritto (1. ${ }^{a}$ ed. 1977), Roma-Bari: Laterza.

- 2011: Saggi sulla scienza giuridica, Torino: Giappichelli.

BURAZIN, L., 2012: «Indirectly and Directly Evaluative Legal Theory: a Reply to Julie Dickson», Diritto \& questioni pubbliche, 12, 182-210.

CHIASSONI, P., 2005: «Concezioni analitiche originarie della meta giurisprudenza. Una rilettura apologetica», Notizie di Politeia, año XXI, núm. 80, 63-101.

${ }^{67}$ No sólo: hay que añadir que el derecho y la actividad de los juristas son vistas con sospecha en cuanto son consideradas entre los principales factores que frenan el crecimiento económico. En la literatura económica contemporánea, los escritos de economistas que se preocupan por demostrar que las sociedades que crecen menos son aquéllas en las que existen muchos juristas y pocos ingenieros representan hoy en día un verdadero y propio género literario. Vid. para todos MURPHY, SHLEIFER y VISHNY, 1991: 503-530.

68 BоввIO, 2007: 37-38, la cursiva aparece en el original. 
— 2013: «Positivismo giuridico», en G. PINO, A. SChiavello y V. Villa (a cura di), Filosofia del diritto. Introduzione critica al pensiero giuridico e al diritto positivo, Torino: Giappichelli, 32-83.

Comanducci, P., 2004: «Problemi di compatibilità tra diritti fondamentali», en P. COMANDUCCI y R. GUASTINI (a cura di), Analisi e diritto 2002-2003. Ricerche di giurisprudenza analitica, Torino: Giappichelli, 317-329.

- 2008: «Conoscere il diritto», Materiali per una storia della cultura giuridica, año XXXVIII, núm. 2, 419-428.

- 2012: «Diritto e senso comune», Analisi e diritto, 77-86.

DiciotTi, E., 2007: «Regola di riconoscimento e concezione retorica del diritto», Diritto \& questioni pubbliche, 7, 9-42.

— 2011: «Sei osservazioni su Del diritto inesistente», Diritto \& questioni pubbliche, 11, 957-981.

DiCKSON, J., 2001: Evaluation and Legal Theory, Oxford-Portland Oregon, Hart.

- 2004: «Methodology in Jurisprudence: a Critical Survey», Legal Theory, 10, 2004, 117-156.

DworkIN, R., 1989: Law's Empire (1988), traducción al castellano: El imperio de la justicia, Barcelona: Gedisa.

- 2010: Justice in Robes (2006), traducción al italiano: La giustizia in toga, Roma-Bari: Laterza.

- 2013: Justice for Hedgehogs (2011), traducción al italiano: Giustizia per i ricci, Milano: Feltrinelli.

FERRAJOLI, L., 2004a: «Diritti fondamentali e democrazia costituzionale», en P. COMANDUCCI y R. GUASTinI (a cura di), Analisi e diritto 2002-2003. Ricerche di giurisprudenza analitica, Torino: Giappichelli, 331-350.

— 2004b: «La pragmatica della teoria del diritto», en P. ComAnduCCI y R. GUASTINI (a cura di), Analisi e diritto 2002-2003. Ricerche di giurisprudenza analitica, Torino: Giappichelli, 351-375.

FinNIS, J. M., 2000: Natural Law and Natural Rights (1992), traducción al castellano: Ley natural $y$ derechos naturales, Buenos Aires: Abeledo Perrot.

FulLeR, L. L., 2005: Positivism and Fidelity to Law. A Reply to Professor Hart (1958), traducción al italiano: Il positivismo e la fedeltà al diritto. Una replica ad Hart, en A. SCHIAVELLO y V. VelluZZI (eds.), Il positivismo giuridico contemporaneo. Una antologia, Torino: Giappichelli, 136-170.

FusELLI, S., 2011: «Forme del giuridico. Materiali per una discussione di un recente volume di Mario Jori», Diritto \& questioni pubbliche, 11, 983-1006.

GADAMER, H. G., 1983: Wabrbeit und Methode (1960), traducción al italiano: Verità e metodo, Milano: Bompiani.

Gallie, W. B., 1956: «Essentially Contested Concepts», Proceedings of the Aristotelian Society, vol. 56, 167-198.

GuASTINI, R., 2004: «Rigidità costituzionale e normatività della scienza giuridica», en P. CoMANDUCCI y R. GUASTINI (a cura di), Analisi e diritto 2002-2003. Ricerche di giurisprudenza analitica, Torino: Giappichelli, 413-416.

- 2011a: «Bobbio sulla scienza giuridica. Introduzione alla lettura», en N. BobBio, Saggi sulla scienza giuridica, Torino: Giappichelli.

— 2011b: La sintassi del diritto, Torino: Giappichelli.

- 2011c: Interpretare e argomentare, Milano: Giuffrè.

GueST, S., 1992: Ronald Dworkin, Edinburgh: Edinburgh University Press.

HART, H. L. A., 1992²: The Concept of Law (1961; 1994²), traducción al castellano: El concepto de derecho, Buenos Aires: Abeledo Perrot. 
IaCono, A. M., 2003: «La giustizia di Trasimaco e i filosofi del sospetto», Ragion Pratica, 20, 167-185.

JORI, M., 1985: «Scienza giuridica e scienze naturali», Materiali per una storia della cultura giuridica, año XV, núm. 2, 423-439.

- 1997: «Uberto Scarpelli e il giuspositivismo», en U. SCARPELLI, Cos'è il positivismo giuridico (1 ${ }^{\text {a }}$ ed. 1965), Napoli: Esi.

- 2004: «Pragmatica, scienza giuridica e diritti», en P. COMANDUCCI y R. GUASTINI (a cura di), Analisi e diritto 2002-2003. Ricerche di giurisprudenza analitica, Torino: Giappichelli, 377-411.

- 2010: Del diritto inesistente. Saggio di metagiurisprudenza descrittiva, Pisa: Ets.

KAFKA, F., 1979: Zur Frage der Gesetze (1920), traducción al italiano: La questione delle leggi, en id., Tutti i racconti, Milano: Mondadori, 403-405.

Kirchmann von, J. H., 1964: Die Wertlosigkeit der Jurisprudenz als Wissenschaft (1948), traducción al italiano: La mancanza di valore della giurisprudenza come scienza, en J. H. KIRCHMANN y E. Wolf, Il valore scientifico della giurisprudenza, Milano: Giuffrè.

KRESS, K., 1987: «The Interpretive Turn», Ethics, 97, 834-860.

MacCormick, N., 1985: «A Moralistic Case for A-Moralistic Law», Valparaiso University Law Review, 20, 1-41.

- 2001: Legal Reasoning and Legal Theory (1978; 1994²), traducción al italiano: Ragionamento giuridico e teoria del diritto, Torino: Giappichelli.

Melville, H., 1992: Moby Dick or the Whale (1851), Wordsworth Classics, Ware.

Moreso, J. J., y Villajosana, J. M., 2004: Introducción a la teoría del derecho, Barcelona-Madrid: Marcial Pons.

Murphy, K. M.; SHLEIfER, A., y Vishny, R. W., 1991: «The Allocation of Talent: Implication for Growth», Quarterly Journal of Economics, 106, 503-530.

Murphy, L., 2001: «The Political Question of the Concept of Law», en J. ColEman (ed.), Hart's Postscript. Essays on the Postscript to The Concept of Law, Oxford, University Press, 371-409.

PATTARO, E., 1976: «Il positivismo giuridico italiano dalla rinascita alla crisi» (ed. or. 1972), en U. SCARPELLi (a cura di), Diritto e analisi del linguaggio, Milano: Edizioni di Comunità, 451-487.

PINO, G., 2013: «Interpretazione cognitiva, interpretazione decisoria, interpretazione creativa», Rivista di filosofia del diritto, 1, 77-101.

PINTORE, A., 1994: «Sulla filosofia giuridica italiana di indirizzo analitico», en M. JORI (a cura di), Ermeneutica e filosofia analitica. Due concezioni del diritto a confronto, Torino: Giappichelli, 243-264.

Platone (1998), La Repubblica, vol. I, Napoli: Bibliopolis.

POGGI, F., 2008: «La questione delle leggi. Brevi osservazioni a margine di un racconto di Franz Kafka», en P. COMANDUCCI y R. GUASTINI (a cura di), Analisi e diritto 2007. Ricerche di giurisprudenza analitica, Torino: Giappichelli, 57-65.

Putnam, H., 1987: Mind, Language and Reality. Philosophical Papers, Volume 2 (1975), traducción al italiano: Mente, linguaggio e realtà, Milano: Adelphi.

Quine, W. V. O., 1969: Two Dogmas of Empiricism (1951), traducción al italiano, Due dogmi dell'empirismo, en A. PASQuinelli (a cura di), Il neoempirismo, Torino: Utet, 861-890.

RAZ, J., 2001: «Two Views of the Nature of the Theory of Law: a Partial Comparison», en J. Coleman (ed.), Hart's Postscript. Essays on the Postscript to The Concept of Law, Oxford: University Press, 1-37. 
- 2005a: Authority, Law and Morality (1994), traducción al italiano: Autorità, diritto e morale, en A. Schiavello y V. Velluzzi (a cura di), Il positivismo giuridico contemporaneo. Una antologia, Torino: Giappichelli, 286-315.

— 2005b: «Can there be a Theory of Law?», en M. P. Golding y W. A. EDMUNDSON (ed.), The Blackwell Guide to the Philosophy of Law and Legal Theory, Oxford: Blackwell, 324-342.

RoRTY, R., 1986: Philosopby and the Mirror of Nature (1979), traducción al italiano: La filosofia e lo specchio della natura, Milano: Bompiani.

RuIz MANERO, J., 2011: «Aclarar lo que, una vez aclarado, resulta obvio. Sobre Del diritto inesistente, de Mario Jori», Diritto E questioni pubbliche, 11, 1007-1024.

SAmuel, G., 2003: Epistemology and Method in Law, Aldershot: Ashgate.

SCHIAVELlo, A., 1998: «Internal point of view: Dworkin a confronto con Hart», en P. ComANDUCCI y R. GUASTINI (a cura di), Analisi e diritto 1997. Ricerche di giurisprudenza analitica, Torino: Giappichelli, 177-197.

— 2002: «Accettazione del diritto e positivismo giuridico», en P. COMANDUCCI y R. GUASTINI (a cura di), Analisi e diritto 2001. Ricerche di giurisprudenza analitica, Torino: Giappichelli, 295-319.

— 2004: «La lungimirante "eterodossia" del positivismo giuridico di Scarpelli», Notizie di Politeia, año XX, núm. 73, 77-89.

SEARLE, J. R., 1996: The Construction of Social Reality (1995), traducción al italiano: La costruzione della realtà sociale, Milano: Edizioni di Comunità.

Stavropoulos, N., 2001: «Hart's Semantics», en J. Coleman (ed.), Hart's Postscript. Essays on the Postscript to The Concept of Law, Oxford: University Press, 59-97.

— 2003: «Interpretivist Theories of Law», en E. N. ZALTA (ed.), Stanford Encyclopedia of Philosophy, bttp://plato.stanford.edu/entries/law-interpretivist/.

TARello, G., 1974: Diritto, enunciati, usi, Bologna: Il Mulino.

Troper, M., 2003: La philosophie du droit (2003), traducción al italiano, Cos'è la filosofia del diritto, Milano, Giuffrè.

Tuzet, G., 2005: «La conoscenza giuridica», Notizie di Politeia, año XXI, núm. 80, 42-62.

VILLA, V., 1984: Teorie della scienza giuridica e teorie delle scienze naturali. Modelli ed analogie, Milano: Giuffrè.

- 1993: Conoscenza giuridica e concetto di diritto positivo. Lezioni di filosofia del diritto, Torino: Giappichelli.

- 1999: Costruttivismo e teorie del diritto, Torino: Giappichelli.

- 2004: Il positivismo giuridico: metodi, teorie e giudizi di valore. Lezioni di filosofia del diritto, Torino: Giappichelli.

- 2011: «Credenze di sfondo, senso comune ed esistenza del diritto. A proposito di un recente libro di Mario Jori», Diritto \& questioni pubbliche, 11, 1025-1045.

- 2012: Una teoria pragmaticamente orientata dell'interpretazione giuridica, Torino: Giappichelli.

— 2013: «Il problema della scienza giuridica», en G. PinO, A. SCHIAVELlo y V. Villa (a cura di), Filosofia del diritto. Introduzione critica al pensiero giuridico e al diritto positivo, Torino: Giappichelli, 374-398.

Viola, F., y Zaccaria, G., 1999: Diritto e interpretazione. Lineamenti di teoria ermeneutica del diritto, Roma-Bari: Laterza.

Williams, B., 1988: Wittgenstein and idealism (1974), traducción al italiano: Wittgenstein e l'idealismo, en M. Andronico, D. Marconi y C. Penco (a cura di), Capire Wittgenstein, Genoa: Marietti, 279-296. 
ZACCARIA, G., 2012: La comprensione del diritto, Roma-Bari: Laterza.

Zagrebelsky, G., 1995: Il diritto mite (1992), Torino: Einaudi, traducción al castellano: El derecho dúctil, Madrid, Trotta.

— 2003: «Ronald Dworkin's principle based constitutionalism: An Italian point of view», International Journal of Constitutional Law, vol. 1, núm. 4, 621-650. 